\title{
SUBALTERNAS NUNCA MAIS! O GRITO DECOLONIAL DAS ESCRITORAS INDÍGENAS BRASILEIRAS
}

Carlos Augusto de Melo Joel Vieira da Silva Filho

Resumo: Esta proposta de trabalho tem por objetivo refletir sobre as experiências de subalternidade e os seus desdobramentos epistemológicos pelos quais as mulheres indígenas têm vivido na sociedade brasileira, a partir das produções literárias de escritoras que se declaram representantes desse grupo étnico, em mais evidência no século XXI. Considerando o que, em seu célebre ensaio Pode o subalterno falar?, Spivak (2010) destaca sobre os mais acentuados processos de subalternização aos quais, ao longo dos séculos, as mulheres são submetidas por questões de gênero, etnia e classe social, - pretendemos discutir a respeito do difícil papel de existência e visibilidade das mulheres indígenas na história da literatura brasileira, o que reflete, inequivocamente, questões de ordem político-social. Assim, este texto parte dessa inquietação para propormos uma leitura literária sobre a importância feminina - em alguns pontos feminista - das escritoras indígenas que, nas últimas décadas, vêm se posicionando contra essa subalternidade imposta pelo pensamento colonial ainda reproduzido na contemporaneidade. Levaremos em conta os protagonismos de Márcia Kambeba, Eliane Potiguara e Graça Graúna, cujas literaturas apresentam necessários posicionamentos de denúncia, de autoafirmação em constante relação ancestral, de uma forma que decolonizam a sociedade e a literatura. Como apoio teórico recorreremos aos estudos de: María Lugones, Catherine Walsh, Aníbal Quijano, entre outros.

Palavras-chave: Literatura indígena. Autoria feminina. Decolonialidade.

Abstract: This work aims to reflect on the experiences of subalternity and its epistemological developments by which indigenous women have faced in Brazilian society, taking into considerations the literary productions of writers who declare themselves representatives of this ethnic group, especifically in the 21st century. Considering her essay Can the subordinate speak?, in which Spivak (2010) highlights about 
the most accentuated processes of subordination to that, over the centuries, women have been subjected to issues of gender, ethnicity and social class, we intend to discuss about the difficult role of existence and visibility of indigenous women in the history of Brazilian literature, that reflects, unequivocally, political and social questions. Thus, this text proposes a literary reading about the feminine importance - in some feminist points - of the indigenous writers who, in the last decades, have been fighting against this subordination imposed by the colonial thought, really reproduced in contemporary times. We will take into account the protagonism of Márcia Kambeba, Eliane Potiguara and Graça Graúna, whose literatures present necessary positions of denunciation, of self-affirmation in constant ancestral relationship, in a way that decolonize society and literature. As theoretical support we will based on the studies of: María Lugones, Catherine Walsh, Aníbal Quijano, and others.

Keywords: Indigenous literature. Female authorship. Decoloniality.

\section{AS MULHERES NA LITERATURA BRASILEIRA: SUBALTERNIZAÇÃO VERSUS EMPODERAMENTO}

Em seu ensaio Cânon (1992), Roberto Reis destaca que todo cânone literário é constituído sob os princípios de seleção e exclusão, nos quais determinados escritores e/ou grupos são escolhidos enquanto tantos outros, excluídos. $\mathrm{O}$ cânone, então, seria um mecanismo segregador, responsável por identificar, selecionar, eleger e validar obras e autores, de acordo com critérios bem específicos, os quais, em contínuas mutações, podem envolver elementos políticos, sociais, históricos, culturais, bem como espaciais, institucionais, educacionais, nacionalistas, artísticos e estéticos. A noção elitizante de que se tinha da literatura, pautada em uma 
supremacia do estético, a partir da qual se pensa na soberania de uma escrita literária "peculiar às elites educadas" (REIS, 1992, p. 72) pode ser questionada. Nesse sentido, torna-se inviável se valer da estreita justificativa - sob a qual parte da crítica e da história tradicionalista mantém seus juízos de valor - de que os nomes selecionados, em um cânone, são aqueles de quem escreveram bem e melhor (na ideia dicotômica de belo e feio platônica, por exemplo), uma vez que o estético não se sustenta sozinho, isoladamente, sobretudo pela própria condição de instituição histórica na qual a literatura está engendrada.

A exclusão de diversos grupos, considerados minoritários na história da literatura nacional, como os indígenas, os negros, os homossexuais, as mulheres, os ciganos, os pobres, explica o caráter parcial pelo qual o cânone literário se estrutura e se orienta, cuja lógica de seleção e exclusão torna-se o espelho do pensamento hegemônico, ideológico e colonialista da sociedade brasileira. Conforme argumenta Roberto Reis:

Ao olharmos para as obras canônicas da literatura ocidental percebemos de imediato a exclusão de diversos grupos sociais, étnicos e sexuais do cânon literário. Entre as obras-primas que compõem o acervo literário da chamada "civilização" não estão representadas outras culturas (isto é, 
africanas, asiáticas, indígenas, muçulmanas), pois o cânon com que usualmente lidamos está centrado no Ocidente e foi erigido no Ocidente, o que significa, por um lado, louvar um tipo de cultura assentada na escrita e no alfabeto (ignorando os agrupamentos sociais organizados em torno da oralidade) [...]. (REIS, 1992, p. 72)

Na história da literatura brasileira, o cânone vem sendo construído em bases deliberadamente machistas, sexistas e misóginas. Em uma breve análise retrospectiva, é perceptível que, até pouco tempo, ele agregava um número significativo de escritores, homens oriundos de grupos sociais, em sua grande maioria, compostos por sujeitos brancos, heterossexuais, de classe social ascendida. Às mulheres escritoras e as suas contribuições literárias deixou-se o mais profundo silenciamento ou, quando muito, um irrisório espaço onde frequentaram apenas aquelas que se encaixavam ao horizonte de expectativas masculinos. Nesse sentido, afirmar que as mulheres possuíram (e, em certa medida, nos dias de hoje possuem) um lugar visível no sistema literário brasileiro não se configura como uma realidade propriamente dita. Por longos anos elas sempre estiveram à margem, subalternizadas, excluídas, sujeitadas a uma dinâmica de generificação, a qual, a partir da perspectiva patriarcal 
brasileira, dominante e hegemônica, tentara prendê-las no mundo privado, familiar e doméstico em um contexto de cultura de herança colonial europeia.

Inclusive, os compêndios escolares de literatura, ou as histórias literárias, mais tradicionais, que procuraram traçar panoramas históricos obsoletos da produção literária no Brasil, pouco ou quase nada falaram sobre a presença e a importância das mulheres. Embora atuantes no circuito literário nacional, desde o século XIX, consideradas de fundamental importância para a formação de nossa literatura, foram sufocadas pelos estereótipos e preconceitos misóginos da visão historiográfica e crítica de nossa elite intelectualizada. Recentemente, ao se propor a analisar o espaço atribuído às escritoras brasileiras em três coleções de livros didáticos do Guia do Programa Nacional do Livro Didático, Ana Cristina Steffen percebe que menos de 10 nomes de mulheres foram "de fato estudados, que ultrapassam uma simples menção" (STEFFEN, 2018, p. 328) em comparação a um número bastante extenso de escritores homens, chegando à conclusão de que é

ainda mais crítico constatar que a presença da autoria feminina dos séculos XVIII e XIX, origem da escrita de mulheres no Brasil, é praticamente nula. $E$ que, mesmo as autoras do século $X X$, surgem majoritariamente 
de forma pouco significativa, superficial. (STEFFEN, 2018, p. 327)

Essas questões relacionam-se com o que a crítica indiana Gayatri Chakravorty Spivak, destaca em seu memorável "Pode o subalterno falar?", no qual se questiona a obliteração do sujeito subalterno pelo discurso hegemônico, com ênfase à completa obscuridade do sujeito feminino:

No contexto do itinerário obliterado do sujeito subalterno, o caminho da diferença sexual é duplamente obliterado. A questão não é a da participação feminina na insurgência ou das regras básicas da divisão sexual do trabalho, pois, em ambos os casos, há "evidência". É mais uma questão de que, apesar de ambos serem objetos da historiografia colonialista e sujeitos da insurgência, a construção ideológica de gênero mantém a dominação masculina. Se, no contexto da produção colonial, o sujeito subalterno não tem história e não pode falar, o sujeito feminino está ainda mais profundamente na obscuridade. (SPIVAK, 2010, p. 66-67)

De fato, não apenas em livros didáticos, mas em todo imaginário intelectual hegemônico, construído forjadamente à base de um machismo estrutural, nos moldes do pensamento colonial, é recorrente o silenciamento das escritoras em nossa formação literária. Poucos nomes eram valorizados e evidenciados pela recepção crítica, como os de Clarice 
Lispector, Rachel de Queirós, Cecília Meireles, Lygia Fagundes Telles, mulheres pertencentes a um núcleo intelectual reconhecido, bem estabelecido, no qual os atributos como classe social alta, orientação heterossexual e cor branca foram condições favoráveis para suas permanências na memória literária nacional. Pode-se dizer que é muito pouco comparado ao grande número de escritoras que também contribuíram para a nossa literatura, em jornais, revistas e livros, inclusive no século XIX, a exemplo de Nísia Floresta, de Francisca Júlia da Silva, de Gilka Machado, de Júlia Lopes de Almeida, bem como de Maria Firmina dos Reis, mulher negra, maranhense, cujo pioneirismo está em sua literatura feminina, anticolonial e antirracista. Essas mulheres são consideradas transgressoras, que, mesmo diante das limitações de seu tempo, foram além do limite do papel social ao qual os homens lhes reservavam.

Entre os séculos XIX e o XXI, diversas outras mulheres que se propunham ao literário continuaram sendo silenciadas reiteradamente, tendo grandes resistências dos intelectuais do sexo masculino, em sua grande maioria; e, poucas sendo inseridas na linha de frente da literatura brasileira, apesar de significativas mudanças do contexto histórico e político do país. Contudo, em fins do século XX em diante, graças 
ao surgimento e fortalecimento da Crítica Feminista, dos Estudos Culturais e dos Discursos e Pensamentos Póscoloniais, Anticoloniais, Descoloniais e Decoloniais, essas escritoras tiveram apoio de trabalhos e pesquisas, oriundos a grosso modo das universidades públicas, interessados pela investigação e revisão da história da literatura de autoria feminina, o que, ao longo das décadas, possibilitaram mudanças epistemológicas paradigmáticas a respeito da recepção das mulheres no ensino e nos circuitos literários em geral.

Pode-se dizer que o grande ponta pé inicial foi dado pelas professoras Zahidé Muzart, Constância Duarte Lima, Norma Telles, Izabel Brandão, Tânia Ramos, cujas pesquisas interinstitucionais voltavam-se para os levantamentos e estudos os sistemáticos de mulheres escritoras no país. O resultado exitoso repercutiu-se no cenário brasileiro, obtendo seus desdobramentos em diversos outros estudos, nas últimas décadas, em todo o país, nas figuras de, por exemplo, Lúcia Zolin, Luciana Borges, Eduardo da Cruz, Anna Faedrich, Ana Rita Santiago, Rosilda Alves, entre tantas/os outras/os.

A partir desse início da ascensão literária do feminino, advinda dos centros e das margens, a violência contra 
os direitos de as escritoras existirem, serem visíveis e ouvidas, de se inscreverem na e pela literatura, oral e/ ou escrita, está sendo destituída de seu poder secular mesmo que vagorosamente -, possível de se ser percebida por meio dos estreitos vínculos literários com as mais diversas manifestações de empoderamentos femininos em movimentos sociais, bem como em representação política, em atuação nas redes sociais, em ocupação de espaços artísticos, intelectuais e universitários, nos quais já se notam trabalhos literários heterogêneos, que, direta ou indiretamente, militante ou não, buscam ser apoios consistentes nas lutas de apoio às mulheres contra o machismo, a misoginia, e a todo tipo de violência e preconceito contra ao sexo feminino, construindo um cenário intelectual de acolhimento e esperanças por meio do que a literatura tem de mais legítimo: a liberdade no sensível das palavras.

Um dos principais feitos dessa produção literária feminina insurgentes é a capacidade que as mulheres têm de autorrepresentação, assumindo suas próprias identidades, com a propriedade de quem está de um lugar de fala à medida que vai possuindo uma perspectiva mais próxima de si, o que difere muito - embora não as invalidem - das 
representações que os homens escreveram do feminino nos textos literários:

Nesse contexto, a literatura de mulheres, historicamente marginalizada, vem ganhando espaço e veiculando uma voz dissonante em relação a esse estado de coisas, sobretudo no que se refere a representações de identidades femininas que, em boa escala, já podem ser consideradas representativas do conjunto das diversas perspectivas sociais das mulheres. E se ainda não é capaz de lhes retratar plenamente a diversidade identitária, certamente avança um bom tanto em relação à literatura hegemônica. (ZOLIN, 2010, p. 194)

Embora o empoderamento literário das mulheres já seja uma realidade brasileira, muitas escritoras ainda têm encontrado outras resistentes barreiras do pensamento neocolonial, além do referido problema de gênero, uma vez que são sufocadas pelos discursos de ódio e juízos de valor, asquerosamente excludentes, relacionados a identidades étnicas e a classes sociais subalternizadas historicamente. Se se considerar a afirmação de Spivak, em seu ensaio "Pode um subalterno falar?", um dos marcos do pensamento pós-colonial, de que se, "no contexto da produção colonial, o sujeito subalterno não tem história e não pode falar, o sujeito subalterno feminino está ainda mais profundamente na obscuridade" (SPIVAK, 2010, p. 
67), é possível acreditar que as formas de subalternização do gênero feminino pela sua condição étnica e social submetem as mulheres pobres, negras e indígenas, por exemplo, à desumana inexistência do sujeito.

Gayatri Spivak aborda a concepção de subalterno como um sujeito invisibilizado e impossibilitado de ser visto e ouvido; é excluído das diversas camadas sociais nas quais perde seus direitos de ser ele próprio (em sua cultura, suas ideologias, suas identidades). Sandra Regina Goulart Almeida, traduzindo o referido texto da pensadora indiana, destaca que o sujeito subalterno é aquele que pertence "as camadas mais baixas da sociedade constituídas pelos modos específicos de exclusão dos mercados, da representação política e legal, e da possibilidade de se tornarem membros plenos no estrato social dominante" (ALMEIDA, 2010, p. 12).

Nessa proposição, estão os grupos considerados minoritários, os quais, aqui, centramos a discussão nas mulheres indígenas, subalternizadas por serem mulheres e indígenas, as quais, em nossa sociedade, é evidente que são postas à margem da margem. Essa constituição do sujeito subalterno parte do poder colonial estar vinculado à violência epistêmica, que, segundo as palavras de Spivak, "é o projeto remotamente orquestrado, vasto e heterogêneo 
de se constituir o sujeito colonial como Outro. Esse projeto é também a obliteração assimétrica do rastro desse Outro em sua precária Subjetividade" (SPIVAK, 2010, p. 47). Desse modo, o sujeito subalterno é destituído de todos os elementos que o tornam sujeito partícipe de um grupo, de um povo. As mulheres são postas nessa situação de obscuridade, impedidas de aparecerem, de forma que são construídas como um Outro.

$\mathrm{Na}$ sociedade ocidental colonialista, as mulheres indígenas são assujeitadas pelos não indígenas por séculos e séculos, desde o período da invasão europeia, sobretudo pelos homens, os quais as submetem a todos os tipos de violência, como, por exemplo, a sexual, a corporal, a intelectual, a psicológica, a emocional, cujas consequências são a degradação de suas identidades e a objetificação de seus corpos. Sentindo-se insultadas e aviltadas, essas indígenas passaram a viver sob o signo da ameaça, do ataque e do medo. Eliane Potiguara relembra o processo de exploração laboral e sexual pelo qual essas mulheres passaram (e passam), a partir da diáspora indígena, impulsionada pela ocidentalização das américas:

As mulheres indígenas também vão trabalhar como operárias mal remuneradas ou nas grandes plantações dos latifundiários, em que um sistema de cativeiro, trocando 
seu trabalho por latas de sardinhas e nunca conseguindo pagar sua dívida com o contratante. Outras vezes, vão morar com homens sem caráter que as transformam em objeto de cama e mesa, submetidas a agressões físicas e parindo dezenas de filhos, para viverem, miseravelmente, nas casas de palafitas na Amazônia, dentro e fora do Brasil, ou sobrevivem em favelas contaminadas moral, social, política e fisicamente. Muitas vezes, trabalham somente pelo prato miserável de comida ou por um pouco de farinha de mandioca

$[\ldots]$

Outra forma de escravidão de mulheres indígenas é a constatação da presença delas em prostíbulos e em zonas de meretrício, onde vendem seu corpo por migalhas, contraindo Aids e outras doenças sexuais. Criando crianças sem futuro, famintas ou portadoras do vírus HIV. (POTIGUARA, 2019, p. 30-31)

Em contexto urbano, obrigadas a enfrentar a alteridade da diáspora, lidam com o preconceito, os olhares de descaso, os comentários da gozação, todo os atos discriminatórios possíveis, os quais reescrevem as histórias dessas mulheres autóctones, do ponto de vista do colonizador - o único que ainda é respeitado pela maioria dos brasileiros -, sob o discurso de naturalização da violação colonial, narrando-se episódios, nos quais, como animais selvagens, eram "pegas no 
laço" para serem domesticadas, civilizadas. Como relembra indignada Aline Pachamama: "Não há mulher indígena 'pega no laço'! Há a mulher indígena que foi e é ameaçada, capturada, violentada, escravizada. Ela é a representação de uma luta silenciosa, que perdura há séculos" (2018, p. 11).

Naturalizou-se a violência contra os direitos de elas falarem, de serem ouvidas, de existirem como indígenas. Esses atos violentos, frutos da covardia humana, impediram-nas de se defenderem, deixando-as fragilizadas diante dos sucessivos ataques, tanto abusivos quanto cobertos de ódio e preconceito, o que, por conseguinte, obrigaram-nas a conviver com seus traumas e seus medos em completo silêncio e invisibilidade. Há tempos as práticas de feminicídio, inclusive no campo do simbólico, contra as mulheres indígenas silenciam-nas, ignorando-as como sujeitos sociais, detentores de seus direitos de existência, cujas opressões quase sempre abafadas pela sociedade brasileira são denunciadas na força do poema "A denúncia", de Eliane Potiguara:

\author{
Ó mulher, vem cá \\ que fizeram do teu falar? \\ ó mulher conta aí... \\ Conta aí da tua trouxa \\ Fala das barras sujas \\ dos teus calos na mão
}


O que te faz viver, mulher?

Bota aí teu armamento.

Diz aí o que te faz calar...

Ah! Mulher enganada

Quem diria que tu sabias falar!

(POTIGUARA, 2019, p. 79)

No uso da linguagem coloquial, traço revelador de uma oralidade comum aos textos da poeta Eliane Potiguara, com o qual é capaz de imprimir certa aproximação ideológica entre os dois interlocutores, na materialidade poética, o texto "A denúncia" apresenta uma situação na qual o sujeito lírico, de gênero indefinido, questiona o silenciamento de uma mulher que, embora referida no singular pelo evidente uso de substantivo, verbo, adjetivo, pronome na segunda ou terceira pessoa do singular ("mulher conta aí", "mulher enganada", por exemplo), parece tomar um papel de representação do gênero feminino de modo geral. Em se tratando do conjunto da obra Metade cara, Metade máscara, de onde esse poema foi retirado, é possível acreditar que essa representação volta-se especialmente às mulheres indígenas brasileiras.

Sensível à trajetória de vida dessa mulher, o sujeito lírico procura incitá-la a falar, em forma de denúncia, sobre as mazelas e as angústias pelas quais tem passado ao longo do tempo por conta do sistema de opressão e subalternização 
sociais. Torna-se claro que, ao questioná-la, ele se propõe a ouvi-la - contrapondo-se ao silenciamento histórica e estruturalmente imposto a ela - contar sua narrativa de vida, compartilhar de suas histórias, todas registradas na memória de seu corpo ("fala das barras sujas/dos teus calos na mão"), meios dos quais pode se utilizar para denunciar as circunstâncias com as quais teve de lidar para chegar ao limite de não poder mais falar, ter de ficar calada. Todavia, o texto indica que, apesar de toda a opressão vivenciada, essa mulher conseguiu sobreviver, tendo ainda motivos para continuar e, se utilizar de seu armamento, poderá seguir adiante, uma vez que ainda sabe/pode falar.

Nos últimos anos, devido ao fortalecimento político das lideranças e organizações indígenas, a história das mulheres indígenas brasileiras tem passado, a duras penas, por algumas, mas também significativas, mudanças e transformações, tendo à frente das urgentes causas femininas a escritora e militante Eliane Potiguara, cuja força e liderança contra a violação dos direitos indígenas das mulheres estão sendo fundamentais para motivar as mulheres dos povos indígenas a mudarem suas vidas e serem protagonistas de suas próprias histórias, reconstruindo e fortalecendo suas identidades, conforme palavras de Aline Pachamama, como verdadeiras "guerreiras": 
Não por estimularmos a guerra ou os conflitos, mas por defendermos os nossos, as nossas memórias, a ancestralidade e a nossa própria vida. Uma vez que terra, sempre desta terra. Quem ensinou às crianças a história do povo que aqui vive, contou a história de outros, não a nossa. A mulher indígena não aparece nas estatísticas de pesquisas relacionadas à violência contra a mulher, à presença no ensino superior ou às atividades políticas e sociais. Mas, estamos aqui. Não apenas em uma voz, mas no coletivo, porque essa é a nossa força. E, a partir da nossa união, mudaremos essas realidades. (PACHAMAMA, 2018, p. 11-12)

A insatisfação de Aline Pachamama relata os ultrajes já sofridos pelas mulheres indígenas, porém, mais que denunciar, ela quer destacar a potência coletiva dessas mulheres que enfrentaram a dor e hoje buscam na união forças para reescrever a história. Na atual cena contemporânea literária brasileira, vemos a ascensão de mulheres indígenas publicando textos e realizando também crítica literária, a exemplo das escritoras indígenas Eliane Potiguara, Graça Graúna, Márcia Kambeba. Inclusive, algumas delas foram e são indicadas a prêmios literários de grande importância no Brasil. De tal forma:

O resultado, sinalizado pelas muitas pesquisas realizadas no âmbito da Crítica Feminista desde os anos 1980 no Brasil, aponta para a re-escritura de trajetórias, 
imagens e desejos femininos. A noção de representação, nesse sentido, se afasta de sua concepção hegemônica, para significar o ato de conferir representatividade à diversidade de percepções sociais, mais especificamente, de identidades femininas antipatriarcais. (ZOLIN, 2009, p. 106)

No Brasil, traçando assim novas formas de representação, as escritoras indígenas conferem outras percepções de mundo, significativamente inovadoras para o sistema literário brasileiro, construindo-o nos firmes alicerces dos pensamentos anticolonialistas, antirracistas, decoloniais. Contrárias à hegemonia masculina, e sob o viés da autonomia feminina, elas estão escrevendo o presente, ressignificando o passado de nossa literatura, que esteve vinculado às normas machistas, misóginas e etnocidas. Nesse sentido, essas representações femininas podem garantir seus lugares no mundo, inspirando e influenciando suas parentes para conhecerem suas identidades, suas ancestralidades, seus feminismos e as suas múltiplas faces. Elas podem confirmar a ideia de que as mulheres nunca foram inferiores no fazer literário, apenas não tiveram as mesmas oportunidades. As conquistas das mulheres na literatura estão acontecendo gradativamente, e sendo uma tarefa contínua, visto que, embora vivamos em uma sociedade contemporânea, a dominação masculina ainda rege muitas das ações em nosso tempo. 
É evidente que as mulheres dos povos indígenas enfrentam os estereótipos e os estigmas de subalternização, os quais foram representados em nossa história da literatura, como no romance Iracema (1865), do escritor romântico José de Alencar, no qual a protagonista da narrativa, a mulher indígena que tem seu nome estampado no título, será conhecida como heroína por cumprir o destino de subalternização, na invasão dos portugueses em territórios indígenas, ao se deixar seduzir e conquistar pelo português Martin, um homem branco, europeu, conquistador, legítimo representante do pensamento colonial, com quem gera um filho, Moacir (filho do sofrimento), por quem se sacrifica para que ele pudesse sobreviver ao parto. Essa criança assume o estatuto mítico de ser o primeiro homem branco a nascer nas terras do Novo Mundo, significando a origem de uma nova nação, equivocadamente associado a um ideal de mestiçagem brasileira, pouco convincente na prática.

Iracema é construída como uma índia frágil, sensível, que não consegue resistir aos encantos, às seduções e ao poder do homem dito "civilizado", preterindo os sujeitos masculinos pertencentes a sua etnia a um lugar da exclusão. Dessa produção literária de Alencar, percebem-se meios pelo qual os cânones literários buscavam destituir a mulher 
indígena enquanto sujeito. Graça Graúna, crítica e escritora indígena diz que "a representação da mulher indígena na sociedade não índia foi articulada, desde a colonização, com requintes de malícia, discriminação, brutalidade, preconceito" (GRAÚNA, 2013, p. 102).

Essa imagem de Iracema proposta em Alencar, dentro da lógica do colonialismo oitocentista, parece perseguir as mulheres indígenas até os dias atuais, como se toda mulher indígena fosse uma Iracema, o que, não realidade, não ocorre. As mulheres indígenas destituem esse passado colonial em suas escritas e negam essa subalternidade, imposta desde quando os colonizadores invadiram as terras que hoje denominamos Brasil. Elas questionam essa subalternidade imposta e do esquecimento, ao qual, muitas vezes são acometidas, construindo, em uma ação coletiva ancestral, uma literatura de denúncia e engajamento, pela qual se autoafirmam enquanto indígenas. Eliane Potiguara destaca que a mulher indígena:

[...] é uma fonte de energias, é intuição, é mulher selvagem, não no sentido primitivo da palavra, mas selvagem como desprovida de vícios de uma sociedade dominante, uma mulher sutil, uma mulher primeira, um espírito em harmonia, uma mulher intuitiva em evolução para com sua sociedade e para com o bem-estar do planeta terra. (POTIGUARA, 2019, p. 46) 
As forças das mulheres indígenas provêm de uma coletividade emanada pelas ancestrais que primeiro resistiram aos projetos coloniais. Trata-se de um movimento de retomada, de decolonização, e usam a escrita literária para questionar e negar o poder colonialista. As mulheres indígenas proclamam que suas vozes não serão mais silenciadas, elas falam de si e dos seus povos, revertendo as amarras coloniais que até os dias de hoje tentam prendê-las em armadilhas de silenciamento. Todas essas ações são mecanismos de luta contra a subalternidade que o sociólogo peruano Aníbal Quijano (2005) chama de colonialidade do poder.

\section{LITERATURA, ESCRITORAS INDÍGENAS E DECOLONIZAÇÃO DO SABER}

A subalternização das mulheres indígenas advém das consequências da colonialidade do poder, a qual, segundo o sociólogo peruano Aníbal Quijano, foi "baseada na imposição da idéia (sic) de raça como instrumento de dominação" (QUIJANO, 2005, p. 136), da qual são integrantes do mesmo processo histórico a colonização das Américas e a formação do pensamento econômico capitalista. Os modelos de dominação e subordinação, reproduzidos dentro do sistema capitalista, reproduzem os mecanismos de classificação e hierarquias sociais por meio de perspectivas étnico-raciais, e 
de gênero, definidas a partir de um centro onde se encontra o colonizador europeu, e da periferia, lugar reservado aos sujeitos considerados inferiores, suscetíveis à dominação econômica, territorial, linguística, cultural. Esse agrupamento hierárquico, sustentado na visão dicotômica: europeu e não europeu, centro e periferia, dominador e subalterno enraizou-se no pensamento ocidental, influenciando práticas colonialistas desastrosas até nos dias atuais.

Desde os debates pós-coloniais, a colonialidade do poder e a diferença colonial são questionadas e problematizadas, inclusive, a partir das contribuições de teóricas/os como Gayatri Spivak, Frantz Fanon e Edward Said. No entanto, apenas as proposições desses críticos não abarcavam as diferentes realidades que envolviam o globo, uma vez que, mesmo sendo teóricos que provinham dos espaços subalternos, a realidade deles diferiam dos espaços latinoamericanos. É nesse influxo que, na década de 1990, o Grupo Modernidade/Colonialidade, liderado por críticos como Walter Mignolo, Aníbal Quijano, Nelson MaldonadoTorres, Enrique Dussel, Catherine Walsh, dentre outros, propôs pensar em um movimento de descolonização/ decolonização. Mignolo destaca que "a opção descolonial é epistêmica, ou seja, ela se desvincula dos fundamentos 
genuínos dos conceitos ocidentais e da acumulação de conhecimento" (2008, p. 290).

O movimento descolonial foi/é fundamental para que as mulheres pudessem ser incluídas nos debates sobre a subalternização imposta pela estrutura colonialista, posto que, até então, percebia-se um apagamento do processo de dominação dos corpos e dos territórios desse grupo feminino. María Lugones, crítica feminista argentina, a partir da noção de colonialidade do poder proposta por Quijano, discute em seu texto Rumo a um feminismo descolonial (2014), a ideia de colonialidade de gênero, propondo que pensemos em um "feminismo descolonial" (LUGONES, 2014, p. 941), pois, na ideia de colonialidade do poder, as mulheres são subalternizadas por serem sujeitos colonizados, por serem mulheres, e assim sucessivamente. Lugones destaca que:

Descolonizar o gênero é necessariamente uma práxis. É decretar uma crítica da opressão de gênero racializada, colonial e capitalista heterossexualizada visando uma transformação vivida do social. Como tal, a descolonização do gênero localiza quem teoriza em meio a pessoas, em uma compreensão histórica, subjetiva/ intersubjetiva da relação oprimir $\neg$ resistir na intersecção de sistemas complexos de opressão. (LUGONES, 2014, p. 940) 
O movimento descolonizador de gênero proposto por Lugones tornou-se essencial para a luta identitária das mulheres escritoras, porque, ao se autorreconhecerem e, também, serem reconhecidas pela sociedade, autoafirmamse como sujeitos de direitos. Pensando a inserção das mulheres indígenas nesse movimento descolonizador, elas podem se unir através de uma coletividade étnica e ancestral, pois, como destaca Lugones "não se resiste sozinha à colonialidade do gênero" (2014, p. 949). Assim, unidas, com o objetivo de denunciar e lutar contra os pensamentos e as estruturas coloniais, historicamente naturalizadas em nosso país, por meio da escrita literária, poderão promover estratégias criativas para que as leitoras indígenas e, também, não indígenas busquem descolonizar-se também.

Como ficou discutido, é sabido que as mulheres brancas, subalternizadas pela perspectiva de gênero, o que dificultou muito as suas inserções e visibilidades no circuito literário nacional, não tiveram de enfrentar o processo de subalternização étnico, responsável, por exemplo, pela colocação das mulheres negras e indígenas em lugares de obscuridade e silenciamento literário, complexos de se desconstruir, problema ainda enfrentado por elas na contemporaneidade. Aqui, então, propõe-se 
que a literatura, em específico a poesia feminina, de autoria indígena brasileira opera como um movimento literário descolonizador de gênero, em que as mulheres indígenas renegam a subalternidade imposta e trazem em seus textos as vozes das ancestrais que já partiram, das que resistem até os dias atuais e das que lutam pelo respeito e valorização das mulheres indígenas. No entanto, o movimento poético feminino indígena utiliza da poesia para cantar a beleza feminina indígena e denunciar essa colonialidade do poder que comprova que os resquícios da colonização ainda resvalam na sociedade atual. Assim:

A escrita indígena é uma forma de autoexpressão de uma resistência que se arrasta e de uma existência que se firma nos moldes de uma sociedade que venda os olhos para um aprendizado com os povos numa atitude reciproca de solidariedade, cuidado, respeito, onde nada é meu, senão que tudo é nosso. (KAMBEBA, 2020, p. 92)

A escritora Eliane Potiguara, mulher indígena do Povo Potiguara, do Litoral Norte da Paraíba, utiliza-se da escrita poética para expressar a resistência feminina indígena. Nascida na periferia do Rio de Janeiro, devido ao desaldeamento histórico dos povos originários pela diáspora, reflexo da colonialidade do poder, ficou reconhecida pela sua poesia, a qual, subvertendo a ordem masculina de 
gênero, grita em tom de denúncia contra a colonização e a colonialidade das mulheres. Os poemas dessa representante indígena evocam a ancestralidade e a memória das anciãs que lutaram primeiro pelo direito de a mulher indígena existir, como podemos verificar no poema "Brasil", presente no livro, publicado em 2004, intitulado Metade Cara, Metade Máscara (2019):

Que faço com a minha cara de índia?

E meus cabelos

E minhas rugas

E minha história

E meus segredos?

Que faço com a minha cara de índia?

E meus espíritos

E minha força

E meu tupã

E meus círculos?

Que faço com a minha cara de índia?

E meu toré

E meu sagrado

E meus "cabocos"

E minha terra

Que faço com a minha cara de índia?

E meu sangue

E minha consciência

E minha luta

E nossos filhos? 
Brasil, o que faço com a minha cara de índia? Não sou violência Ou estupro

Eu sou história

Eu sou cunhã Barriga brasileira Ventre sagrado Povo brasileiro

Ventre que gerou O povo brasileiro Hoje está só ...

A barriga da mãe fecunda

E os cânticos que outrora cantavam Hoje são gritos de guerra Contra o massacre imundo. (POTIGUARA, 2019, p. 32-33)

Neste poema, pode-se observar uma voz feminina que se autodeclara indígena, utilizando-se ironicamente da reiterada expressão "cara de índia", encontrada com muita frequência no discurso coloquial de opressão do sujeito colonial, bem como de elementos pertencentes a seu universo identitário e ancestral, como "tupã", "toré", entre outros. Esse sujeito poético questiona um interlocutor, não identificado até a oitava estrofe, sobre o que fazer com sua "cara de índia", o que, no sentido conotativo, quer significar sua própria identidade étnica, a qual vai além do fenótipo. É interessante observar que, até a oitava estrofe, o texto constrói-se pela alternância entre monóstico ("Que faço 
com a minha cara de índia?"), utilizado reiteradamente como espécie de refrão, causando efeito de indignação do sujeito lírico, e, também, quartetos, todos construídos pelo uso de polissíndeto, causando a repetido da conjunção "e" no início de cada versos. Já da nona estrofe em diante, há uma quebra dessa regularidade dos versos, momento em que é colocado ou evidenciado um interlocutor, com o uso do vocativo "Brasil" ("Brasil, o que faço com a minha cara de índia?"), conduzindo ao desfecho emblemático do poema, cujos questionamentos são deixados de lado, uma vez que serão colocada ênfase nas respostas sobre sua identidade indígena feminina. A sensação é de que a voz poética se coloca em uma posição de enfrentamento, cujo interlocutor, "Brasil", funciona como alegoria do colonialismo, enfrentando-o, subvertendo a lógica de submissão, como sinal de negar à imposição dessa nacionalidade brasileira. Trata-se de uma prestação de contas pela terra invadida, pelas leis não cumpridas.

Desse modo, constituído por cinco estrofes de um verso apenas com a pergunta "Que faço com minha cara de índia?", que se intercalam com estrofes de quatro versos, nelas, a voz indígena do poema, regida pela dúvida, e pela inquietação, ao indagar, vai acrescentando elementos que a constituem 
como sujeito pertencente aos povos originários. Nota-se que, após a estrofe de um verso, a que segue, acrescenta novos questionamentos de constituição identitária ("E meu cabelos / E minhas rugas / E minha história / E meus segredos?"). Ela acrescenta elementos corporais como cabelos e rugas, e, também, ancestrais, como suas histórias e seus segredos. $\mathrm{O}$ corpo dessa mulher indígena pode ser visto como carregado das marcas de sofrimento coloniais, mas também do tecido de memória tramado pela história e pelo segredo; é um corpo que fala, que sente, que anuncia. Nesse sentido, vêse que, na terceira estrofe do poema, nos questionamentos que seguem à pergunta sobre o que fazer com a sua cara de índia, a voz poética aborda uma relação espiritual e corporal das mulheres indígenas: "E meus espíritos / E minha força / E meu Tupã / E meus círculos?". A relação espiritual ancestral não pode ser perdida, portanto, o que fazer? Como reagir? 0 poema apresenta que o sagrado se manifesta na construção da força da mulher, pois os encantados como Tupã são os que regem a força cosmogônica do feminino que não vive sem a presença do sagrado - corpo e espírito em união pela natureza na consolidação da identidade feminina indígena.

Mais adiante, a voz do poema continua a se questionar: "E meu Toré / E meu sagrado / E meus "cabocos" / E minha 
Terra?". Observa-se que, nessa estrofe, as marcações nas palavras "Toré" e "Terra" são grafadas com iniciais maiúsculas. O Toré, a dança em que o sagrado se emana, é respeitado e cantado, é espaço no qual também os "cabocos", protetores dos indígenas, agenciam a preservação da cultura e da cosmovisão indígena. Espaço em que a Terra, local da troca de conhecimentos, do plantio, espaço de (sobre)vivência. O Toré, os Cabocos, a Terra, são elementos sagrados, respeitados. A voz poética feminina do poema vai agenciando os elementos que agregam na constituição da identidade indígena dela própria - destaque para a relação ancestral que a mulher mantém com o sagrado, mantendo uma promoção coletiva, visto que na Terra no qual ela habita, o sagrado se emana para o coletivo. Assim, o que destaca Heliene Costa (2020) em sua tese de doutoramento, é bastante pertinente. Ela afirma que:

No escopo da literatura contemporânea, de autoria indígena no Brasil, a expressão das subjetividades femininas é particularmente reveladora de uma cosmovisão calcada em profunda conexão com as forças da natureza e com a espiritualidade indígena. (COSTA, 2020, p. 22)

Essa cosmovisão centrada nas relações com a natureza e com a espiritualidade expressa a potência subjetiva das 
mulheres indígenas, na vida e no texto literário. Na quarta e última estrofe de quatro versos que segue a pergunta central do poema, a voz feminina diz: "E meu sangue / $E$ minha consciência / E minha luta / E meus filhos?". Aqui, vemos a presentificação de itens de resistência. Nota-se a voz indígena destacando questões que a tornam uma mulher de força. O sangue que pulsa (outrora derramado), a consciência que se mantém firme, em meio aos abalos, a luta que não cessa em meio às perseguições e os filhos que são o futuro, que precisam viver para continuar a tradição, a luta. Os elementos destacados até então após a pergunta "o que faço com minha cara de índia", juntos, formam a mulher indígena que vive da ancestralidade coletiva. Além de sua cara de índia, ela é constituída de seu sagrado, se sua Terra, de sua força, de seu sangue, de seu Toré, e de tantos outros mecanismos que a fortificam e a definem. Após isso, a voz do poema se questiona pela última vez, agora, direcionando ao interlocutor Brasil, a sua pergunta: "Brasil, o que faço com minha cara de índia?". O que segue, não são mais perguntas, mas sim afirmações do que ela (enquanto mulher indígena) é e não é.

A voz indígena continua o narrar poético exclamando: "Não sou violência / Ou estupro". Observamos que a voz 
do poema traz muito desse feminismo descolonial do qual fala Lugones (2014), ela nega a violência ao corpo da mulher indígena, denuncia a ação colonial que objetifica, corporifica ou anula a mulher indígena, oprimindo-a, negligenciando o seu direito de existir da forma como ela é, com seus costumes, suas crenças, seu corpo performático. A negação à violência e ao estupro é uma constante das mulheres indígenas, vítimas dessas ações coloniais sexistas, machistas e abusadoras que roubavam a liberdade de seus corpos, tornando-os invadidos fisicamente e na alma.

Após as denúncias, a voz feminina conclui o seu narrar por meio de uma estrofe de doze versos, anunciando o que a constitui, o que a forma, a caracteriza: "Eu sou história / Eu sou cunhã / Barriga brasileira / ventre sagrado / Povo brasileiro / Ventre que gerou / O povo brasileiro / Hoje está só...". Observamos que a mulher indígena do poema se coloca como fundadora na nação brasileira. Ao aceitar a ideia de ser brasileira, ela não aceita passivamente a invasão/colonização que fez com que este país se chamasse Brasil. Ela destaca que, através da barriga, inicialmente pela formação do seu povo, dando à luz aos seus filhos, gerou os primeiros povos; depois, vale lembrar que muitas mulheres indígenas foram vítimas do estupro e geraram o povo 
brasileiro através do sofrimento, da imposição e do sexo forçado. Esse ventre que gerou filhos é sagrado, ventre que, embora machucado pela intromissão do colonizador, não abandonou seus filhos.

Muitas vidas que vieram depois da invasão foram resultado de estupro. A voz indígena do poema não dociliza esse acontecimento, ela denuncia. Vítimas de um poder colonial massacrante, estruturado para impor (o que resultou em mortes, porque houve resistência a esse projeto). Quijano destaca que "toda estrutura de poder é sempre, parcial ou totalmente, a imposição de alguns, frequentemente certo grupo, sobre os demais" (2005, p. 130). Assim, apesar dessa supremacia colonizadora, as mulheres indígenas resistiram e resistem a esse projeto colonial. O encerramento do poema diz bastante dessa ação descolonial feminina indígena: "A barriga da mãe fecunda / E os cânticos que outrora cantavam / Hoje são gritos de guerra / Contra o massacre imundo". O poema se encerra com essa denúncia da voz feminina indígena. As filhas que saíram do ventre que gerou o povo brasileiro não aceitam a subalternidade e o que aprenderam com suas mães e avós refletem em gritos de resistência, contra esse "massacre imundo", que outrora começou e que até os dias de hoje quer dominar corpos e vidas indígenas. 
Outra mulher indígena que descoloniza por meio da literatura é a escritora, e também, professora e crítica literária indígena, Graça Graúna, nascida em São José do Campestre, Rio Grande do Norte, e filha dos Potiguara. Graúna é um dos principais nomes da literatura indígena no Brasil, tanto por sua escrita quanto pela crítica. Doutora em Teoria da Literatura pela Universidade Federal de Pernambuco, ela se destaca em um campo que por longos anos foi negado aos povos indígenas (principalmente às mulheres). Escritora de narrativas e de poemas, revela nos textos a marca ancestral e realiza denúncias, declamando sobre a vivência (ou não) em comunidade indígena e, também, aborda questões que envolvem os povos não-indígenas, mas considerados também subalternos. Trazemos o poema "Terra à vi\$̦ta", que compõe o livro Canto Mestizo, publicado em 1999.

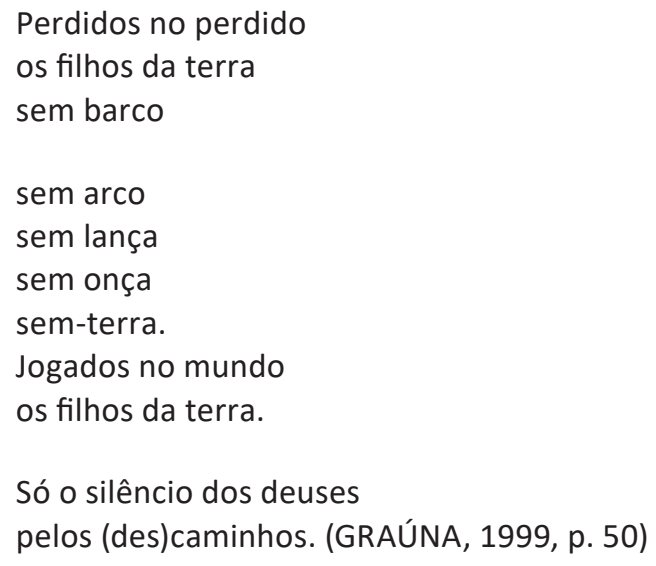


Em sua estrutura o poema apresenta quatro estrofes, três de dois versos e uma de quatro versos. Vale destacar que desde o título do poema uma denúncia já é feita, note-se que no título "Terra à vi\$̣ta", a palavra vista está marcada com um cifrão, mostrando que a terra que fora avistada estava prestes a ser explorada. Um terra em que o que apenas valeria seria o lucro, o dinheiro. Entendemos que o poema questiona a chegada dos colonizadores, que, ao avistarem as terras "brasileiras" almejaram apenas o lucro e, para isso, não importava o método que fosse usado, o que fora visto, precisava ser explorado. A proposição de Quijano é válida neste debate, pois, como destaca o crítico “[...] os povos conquistados e dominados foram postos numa situação natural de inferioridade, e consequentemente também seus traços fenotípicos, bem como suas descobertas mentais e culturais" (QUIJANO, 2005, p. 118). Assim, o poema abordará essa dominação do colonizador que deixa o colonizado numa situação de inferioridade.

A primeira estrofe composta por dois versos aponta uma questão bastante pertinente: "Perdidos no perdido / os filhos da terra". Os perdidos são os indígenas, e o perdido a própria terra que eles habitavam e do qual eram filhos. Quando os colonizadores chegam e veem terra à vista, os 
habitantes daquelas terras, vítimas da invasão, perdem muito da relação que mantinham com o espaço que viviam. Agora, estavam perdidos nos próprios espaços. Na segunda estrofe, a repetição da preposição "sem" configura um movimento anafórico. A preposição é repetida nos cinco versos da estrofes, dando uma dimensão de cansaço aos sujeitos indígenas que estão "perdidos no perdido". A repetição do sem dá um ritmo quase que cantado ao poema e provoca um certo cansaço no leitor (devido a rapidez da leitura que provoca a falta de fôlego), é como se os indígenas que estavam perdidos, estivessem a correr para se salvar, portanto, estavam "sem barco / sem arco / sem lança / sem onça / sem terra".

Em sua poesia, Graça Graúna remonta a um passado colonial que vitimou indígenas por serem contrários aos processos de imposição ao trabalho braçal e forçado, naquela terra que estava "à vișta". Através da palavra poética, Graúna denuncia os malefícios do poder colonial. Rita Olivieri-Godet (2018, p. 39) destaca que "o discurso poético de Graça Graúna é permeado por referências à história da violência contra os índios e à memória dos saberes ancestrais". De fato, o poema aqui em análise remete-nos a um passado violento, aos quais, seus resquícios são vistos 
até os dias atuais. No entanto, Olivieri-Godet (2018) destaca também que a poesia de Graça Graúna tem por objetivo reacender a memória ancestral dos povos indígenas e colaborar para a reconstrução de uma identidade que se emancipa nos dias atuais, em contraposição aos discursos coloniais e subalternizantes.

No poema, diferente do que é dito na primeira estrofe, a terceira anuncia que os filhos da terra estão "jogados no mundo", sem nada, apenas jogados, após perderem tudo. $E$, o que resta é o "silêncio dos deuses" que acompanhaos pelos "(des)caminhos". A denúncia realizada no poema revela vozes que silenciadas não aceitam essa passividade. Descolonizar através do texto literário também faz-se necessário. Francisco Danner e Fernando Danner em parceria com a escritora e pesquisador indígena Julie Dorrico ao debaterem sobre o movimento descolonial destacam que:

O movimento descolonizador por excelência é e se define por esse caminho e por essa postura das minorias que rompem com o silenciamento, a invisibilização e o privatismo, aos quais foram empurradas ao longo da colonização, e assumem uma atitude pública, política e cultural de militância, de ativismo e de engajamento em torno à sua condição e à sua causa como minorias. (DANNER; DORRICO; DANNER, 2020, p. 68) 
Romper com o silenciamento imposto faz parte de um ativismo que busca questionar os resquícios coloniais e teorizar sob uma ótica autônoma e compromissada com a descolonização da teoria e do pensamento. As mulheres indígenas, a exemplo de Eliane Potiguara, Graça Graúna, Márcia Kambeba e diversas outras visam problematizar essa lógica que é colonizante, elitista e patriarcal. Graça Graúna, através de uma voz poética preocupada com aqueles que estavam "perdidos no perdido", destaca que, embora estejam sem nada, são protegidos pelos deuses através do silêncio - e continuam seus caminhos, hoje, não mais perdidos, pois estão na buscam pela retomada.

A escritora indígena Márcia Kambeba, do povo Omágua/ Kambeba, do estado do Amazonas, traz, em seu livro Ay Kakyri Tama: Eu moro na cidade, poemas que assumem uma atitude política, engajada e educativa. Esse livro foi publicado, apenas em versão digital, em 2013 pela editora Grafisa de Manaus. Anos depois, em 2018, teve sua reedição impressa, com algumas modificações - das quais não se falarão aqui -, pela editora Pólen em São Paulo.

O poema que dá nome ao livro servirá de exemplo para se analisar como a potência criativa da escritora indígena convoca os leitores, indígenas e não indígenas, a novas reflexões sobre os povos originários das Américas: 
Ay kakyri tama.

Ynua tama verano y tana rytama

Ruaia manuta tana cultura ymimiua

Sany may-tini, iapã iapuraxi tanu ritual

[tradução]

Eu moro na cidade

Esta cidade também é nossa aldeia

Não apagamos nossa cultura ancestral

Vem homem branco, vamos dançar nosso ritual.

Nasci na Uka sagrada

Na mata por tempos vivi

$\mathrm{Na}$ terra dos povos indígenas

Sou Wayna, filha da mãe Aracy

Minha casa era feita de palha

Simples, na aldeia cresci

Na lembrança que trago agora

De um lugar que eu nunca esqueci

Meu canto era bem diferente

Cantava na língua Tupi

Hoje, meu canto guerreiro

Se une aos Kambeba

aos Tembé, aos Guarani

Hoje, no mundo em que vivo

Minha selva em pedra se tornou

Não tenho a calma de outrora

Minha rotina também já mudou

Em convívio com a sociedade

Minha cara de "índia" não se transformou

Posso ser quem tu és

Sem perder quem sou 
Mantenho meu ser indígena

Na minha Identidade

Falando da importância do meu povo

Mesmo vivendo na cidade.

(KAMBEBA, 2018, p. 24-25)

O poema da escritora Márcia Kambeba é composto por oito estrofes (contando com estrofe na língua indígena). A primeira estrofe está escrita na língua Omágua/Kambeba, o que já aponta uma ação descolonizadora. A voz indígena do poema apontará no decorrer dos versos que, apesar de estar na cidade ela não deixa de ser indígena. Assim, o poema funciona como um elemento de autoafirmação e de denúncia. A voz indígena convoca os brancos e também os indígenas a compreenderem que o sujeito indígena não perde sua identidade quando sai da aldeia, mas a leva consigo, como dito no terceiro verso da primeira estrofe: "Não apagamos nossa cultura ancestral", pois, de fato, isso não é perdido, deixado ou anulado.

Na segunda estrofe a voz indígena se apresenta como "Wayna, filha de Aracy", nascida na "Uka sagrada". Os elementos da aldeia, da comunidade, aparecem no poema como reafirmação da identidade. Estar fora da aldeia é manter a Uka sagrada dentro de si, manter sua ancestralidade e as ações aprendidas com os povos da comunidade. As lembranças do ambiente vivido jamais são 
apagadas, como dito na terceira estrofe: "Na lembrança que trago aqui / De um lugar que nunca esqueci". Note-se que este poema abordada uma questão muito pertinente enfrentada por diversos povos indígenas, a necessidade de sair da aldeia, na busca por formação acadêmica, trabalho, dentre outros. Porém, esses sujeitos que saem, levam suas memórias e lembranças e são responsáveis por darem um retorno do aprendido fora para a comunidade. Assim, Márcia Kambeba propõe no poema uma voz feminina autônoma que se autoafirma e diz que, embora fora da aldeia, mantém o compromisso com seu povo. A voz política da escritora se equipara a voz da narradora poética, ambas as vozes descolonizam as mentes.

Esse posicionamento político inscrito na literatura de Márcia Kambeba quer ajudar na decolonização dos povos indígenas. Como proposta decolonial, percebe-se que essa escritora procura colaborar para que seus parentes garantam seus lugares de fala, uma vez que, segundo Catherine Walsh, a decolonialidade é um projeto coletivo, que nega o eurocentrismo, buscando "forças, iniciativas e perspectivas éticas que fazem questionar, transformar, sacudir, rearticular e construir" (2009, p. 25). Assim, escritoras indígenas como Márcia Kambeba une forças 
literárias, tendo suas ancestralidades como inspiração, para realizarem esse movimento questionador e transformador do qual fala Walsh. As estrofes finais do poema "Ay Kakyri Tama: Eu moro na cidade" revelam essa ação decolonial.

Revelando que a língua do seu povo se mantém viva, Wayna, a voz indígena do poema destaca que, mesmo vivendo na selva em pedra (cidade), espaço que, diferente da aldeia não oferece calma e tranquilidade, sua cara de "índia" não se transformou. De certa maneira, essa questão se aproxima do referido poema de Eliane Potiguara, como se as autoras tivessem a necessidade de confirmar sua identidade ressignificando a expressão pejorativa "cara de índia", utilizada pelos racistas para confirmar a identidade indígena baseada no fenótipo. A essência indígena da personagem se mantém, e ela mesmo afirma "Posso ser quem tu és / Sem perder quem sou".

A última estrofe destaca a força identitária e o orgulho de Kambeba em ser indígena, pois, mesmo na cidade, ela fala da importância do seu povo, da sua cultura, da sua identidade, o que faz lembrar das palavras de Graça Graúna: o/a indígena, "onde quer que vá, leva dentro de si a aldeia" (GRAÚNA, 2013, p. 59). Desse modo, por meio da escrita poética, Márcia Kambeba traz uma voz decolonial que defende a 
sua identidade seja na aldeia ou na cidade. A poesia tem o poder de anunciar, denunciar, responder, orientar, educar. Ela mesma destaca que "com a poesia conseguimos refletir nossas ações, reações, preconceitos, buscando aprender a conviver com as diferenças" (KAMBEBA, 2020, p. 94).

A literatura colabora para que as vozes femininas subversivas dos povos indígenas possam anunciar, mas, também denunciar no sistema cultural brasileira, subvertendo a lógica do colonialismo e, com a palavra da poesia, da narrativa, do conto, resistindo à subalternidade. Elas falam e buscam ser ouvidas, produzem textos de qualidade estética, seja nos moldes tradicionais ou contemporâneos, convocando outras mulheres indígenas a decolonizar coletivamente, levando consigo um dos aprendizados ancestrais: a potência da coletividade.

Em Eliane Potiguara, Graça Graúna e Márcia Kambeba o grito decolonial se costura ao texto poético. As vozes dessas mulheres indígenas juntas proclamam uma coletividade identitária, construída desde os tempos mais antigos. Ao fazerem uso da literatura para se autorrepresentarem, para anunciarem a beleza de ser indígena, elas também convocam os leitores indígenas e não indígenas a compreenderem a potência da existência e da resistência, pois, como destaca 
Costa "[...] a resistência das mulheres através da escrita literária, representa uma possibilidade de superação do apagamento de suas memórias e suas subjetividades" (2020, p. 24). Resistir à invisibilidade, ao poder colonial, para que então novas histórias possam ser contadas pelo próprio colonizado e não mais pelo colonizador.

\section{NÃO À SUBALTERNIZAÇÃO! CONSIDERAÇÕES FINAIS}

Resistir à subalternidade que é um elemento de poder colonial não se configura tarefa simples e fácil. Nos estudos literários, as mulheres realizam essa ação de sair da subalternidade desde a década de 1980. No entanto, esse processo é configurado por bases epistêmicas para se construir uma teoria autônoma que questione e lute contra a repressão e ao poder patriarcal que vigora na cena literária brasileira e mundial. Mesmo não aparecendo nos compêndios e manuais de literatura, as mulheres não se deixam silenciar, embora o silenciamento seja um política efetiva da colonialidade do poder.

A pergunta de Spivak se o sujeito subalterno feminino pode falar, feita na década de 1980 ainda ecoa até os dias de hoje. O movimento descolonial feminista destacado por Lugones (2014) exerce incansáveis movimentos para que as mulheres possam falar e se fazerem ouvidas. Neste 
texto não negamos as proposições de Spivak acerca da subalternidade, mas, questionamos o fato de a mulher indígena ser subalternizada pelo poder colonial e às vezes até mesmo dentro dos estudos subalternos.

É para romper com essa lógica dominante, que trouxemos as poesias de Eliane Potiguara, Graça Graúna e Márcia Kambeba, pois, essas mulheres indígenas negam essa dominação e se impõem como produtoras de literatura que decolonizam a escrita, denunciando e tecendo formas poéticas de anunciar pelas quais as mulheres indígenas podem e devem falar em liberdade, quando se sentirem à vontade, quando desejarem. Elas emergem da subalternidade para falar por elas e pelas que foram silenciadas e (ainda) não conseguiram falar.

\section{REFERÊNCIAS}

BALLESTRIN, Luciana. América Latina e o giro decolonial. Brasília: Revista Brasileira de Ciência Política, n.11, p. 89-117, 2013.

COSTA, Heliene Rosa da. Identidades e ancestralidades das mulheres indígenas na poética de Eliane Potiguara. 2020. Tese (Doutorado em Estudos Literários) - Universidade Federal de Uberlândia, Minas Gerais, 2020.

DANNER, Leno Francisco; DORRICO, Julie; DANNER, Fernando.

Decolonialidade, lugar de fala e voz-práxis estético-literária: reflexões desde a literatura indígena brasileira. v. 22/1. ALEA: Rio de Janeiro, $p$. 59-74, janeiro-abril de 2020.

GRAÚNA, Graça. Canto Mestizo. Maricá-RJ: Blocos, 1999. 
GRAÚNA, Graça. Contrapontos da literatura indígena contemporânea no Brasil. Belo Horizonte: Mazza Edições, 2013.

KAMBEBA, Márcia. Ay Kakyri Tama: Eu moro na cidade. São Paulo: Polén, 2018.

KAMBEBA, Márcia Wayna. O olhar da palavra: escrita de resistência. In: DORRICO, Julie; DANNER, Leno Francisco; DANNER, Fernando (Orgs.). Literatura indígena brasileira contemporânea: autoria, autonomia, ativismo. Porto Alegre, RS: Editora Fi, p. 89-98, 2020.

LUGONES, María. Rumo a um feminismo descolonial. Tradução de Juliana Watson e Tatiana Nascimento. Florianópolis: Estudos Feministas, p. 935953, 2014.

MIGNOLO, Walter. Desobediência epistêmica: a opção descolonial e o significado de identidade em política. Tradução de Ângela Lopes Norte. Cadernos de Letras da UFF - Dossiê: Literatura, língua e identidade, $\mathrm{n}$. 34, p. 287-324, 2008.

PACHAMAMA, Aline Rochedo (Churiah Puri). Guerreiras (M'baima Miliguapy): mulheres indígenas na cidade, mulheres indígenas na aldeia. Rio de Janeiro: Editora Pachamama, 2018.

POTIGUARA, Eliane. Metade cara, metade máscara. 3. ed. revisada. Rio de Janeiro: GRUMIM, 2019.

REIS, Roberto. Cânon. In: JOBIM, J. L. (Org.). Palavras da crítica.

Tendências e conceitos no estudo da Literatura. Rio de Janeiro: Imago, p. 65-92, 1992.

SPIVAK, Gayatri Chakravorty. Pode o subalterno falar? Tradução de Sandra Regina G. Almeida, Marcos P. Feitosa e André P. Feitosa. São Paulo: Editora UFMG, 2010.

STEFFEN, Ana Cristina. A (não) presença da literatura de autoria feminina nos livros didáticos de ensino médio. Revista Entrelaces, v. 1, n. 11, p. 315-332, janeiro/março de 2018.

OLIVIERI-GODET, Rita. Graça Graúna: a poesia como estratégia de sobrevivência. Pontos de Interrogação, v. 8, n. 1, p. 33-49, janeiro-junho de 2018. 
QUIJANO, Aníbal. Colonialidade do poder, Eurocentrismo e América Latina. Buenos Aires: CLACSO, Consejo Latinoamericano de Ciencias Sociales, 2005.

WALSH, Catherine. Interculturalidade crítica e pedagogia decolonial: in-surgir, re-existir e re-viver. In: CANDAU, Vera Maria (Org.). Educação intercultural na América Latina: entre concepções, tensões e propostas. Rio de Janeiro: 7 Letras, p. 12-43, 2009.

ZOLIN, Lúcia Osana. A literatura de autoria feminina brasileira no contexto da pós-modernidade. Juiz de Fora: Ipotesi, v. 13, n. 2, p. 105116, julho/dezembro de 2009.

\section{Carlos Augusto de Melo}

Doutor em Teoria e História Literária pela Unicamp.

Professor de Literatura na graduação do Instituto de Letras e Linguística (ILEEL) e na Universidade Federal de Uberlândia (UFU).

Atua nos cursos de Doutorado e Mestrado no do Programa de Pósgraduação em Estudos Literários (PPLET).

Lattes: http://lattes.cnpq.br/5205243411665484

E-mail: carlosaug.melo@gmail.com

ORCID: https://orcid.org/0000-0001-9305-9519

\section{Joel Vieira da Silva Filho}

Mestrando em Estudos Literários no Programa de Pós-Graduação em Linguística e Literatura (PPGLL) na Universidade Federal de Alagoas (UFAL) e pesquisador bolsista CAPES.

Lattes: http://lattes.cnpq.br/5581264177281708

E-mail: joel.filho17@outlook.com

ORCID: https://orcid.org/0000-0001-9895-9911 